\title{
Valoração das Áreas de Preservação Permanente na Bacia do Rio Alegre-ES
}

\author{
Carlos Antonio Alvares Soares Ribeiro, Márcio Lopes da Silva, \\ Naisy Silva Soares, Renata Rodrigues de Castro Rocha, \\ Ângelo Marcos Santos Oliveira
}

Departamento de Engenharia Florestal - DEF, Universidade Federal de Viçosa - UFV

\begin{abstract}
RESUMO
Em um ambiente de sistemas de informações geográficas, analisou-se o impacto econômico decorrente da aplicação do Código Florestal Brasileiro, tendo-se por base a delimitação das áreas de preservação permanente (APPs) na bacia do Rio Alegre, Alegre - ES. Identificaramse os conflitos de uso da terra, determinaram-se o valor econômico das terras e a anuidade equivalente às atividades produtivas em APPs. Verificou-se que a exploração econômica dessas áreas gera, aproximadamente, $\mathrm{R} \$ 1$ milhão por ano, o que equivale a uma contribuição mensal líquida de R\$11 por ha de APP desmatado. Concluiu-se que a implementação de políticas de estímulo à preservação ambiental é viável e necessária.
\end{abstract}

Palavras-chave: área de preservação permanente, Bacia do Rio Alegre, sistema de informações geográficas, políticas ambientais, pequena propriedade.

\section{Economic Impact of Implementation of Permanent Preservation Areas in the Alegre River Watershed, Municipality of Alegre, Espírito Santo State}

\begin{abstract}
This GIS-based study analyzed the economic impact resulting from law enforcement of the Brazilian Forestry Code in relation to demarcation and implementation of permanent preservation areas (PPA's) in the Alegre river watershed, Alegre - ES. Using the Faustmann formula, the total annual net revenue resulting from productive activities for these areas was found to be approximately R $\$ 1$ million. This figures led to the conclusion that the monthly net contribution of each hectare of deforested PPA's is only R $\$ 11$. Thus, the implementation of policies as incentives for environmental preservation is not only feasible but necessary.
\end{abstract}

Keywords: permanent preservation areas, Alegre River Watershed, geography information system, environmental policies, short properties. 


\section{INTRODUÇÃO}

As áreas de preservação permanente (APPs), previstas no Código Florestal, têm a função precípua de proteger o meio ambiente e assegurar-lhe a perpetuidade e o seu papel de prover o bem-estar das populações humanas. Depreende-se daí que a legislação ambiental é justa em seus propósitos. A rigor, no entanto, ela não vem sendo cumprida. Alguns proprietários rurais têm levantado ações indenizatórias contra o Estado por causa da instituição das APPs e das Reservas Legais em suas propriedades (Benjamin, 2000). Isto reflete a reação à perda da renda gerada nas áreas anteriormente voltadas para as atividades agropastoris e silviculturais. Este impasse repete-se em todo o território nacional.

Para se avaliar a dimensão do impacto econômico da supressão dessas atividades ilícitas, bem como para se estabelecer uma base sólida para o cálculo de sanções que, de fato, desestimulem a produção em áreas de preservação permanente, antes de qualquer coisa há que se mensurar a renda periódica auferida nessas circunstâncias. Nascimento (2004) elaborou o diagnóstico ambiental da bacia do rio Alegre, no município de Alegre, ES, identificando as classes de uso e ocupação da terra e as áreas de preservação permanente, com base no Código Florestal (Brasil, 1965) e na Resolução no 303/2002 do Conselho Nacional de Meio Ambiente (CONAMA). Além disso, quantificou a ocorrência de uso da terra à margem da legislação. As características peculiares da estrutura fundiária dessa bacia, em que predominam minifúndios, o relevo é acidentado, a produção agropecuária é artesanal (intensiva no uso da terra e da mão de obra familiar) (Lani, 1987; Resende et al., 1993), compõem um cenário ideal para se testar a veracidade do argumento muito generalizado de que a plena conformidade com a legislação ambiental vigente inviabiliza a produção rural em pequena escala.

Neste contexto, o presente estudo tem como objetivo principal estimar o aporte periódico de recursos na economia regional originado da exploração de áreas de preservação permanente. Essa informação é o ponto de partida para se aquilatar, com fundamentação, o impacto econômico decorrente do fiel cumprimento do Código Florestal Brasileiro naquelas terras.

\section{MATERIAL E MÉTODOS}

\subsection{Caracterização da área de estudo}

A área de estudo corresponde à bacia do rio Alegre. Localiza-se entre os meridianos $41^{\circ} 28^{\prime} \mathrm{e}$ $41^{\circ} 37^{\prime}$ de longitude oeste de Greenwich e entre os paralelos $20^{\circ} 43^{\prime}$ e $20^{\circ} 55^{\prime}$ de latitude sul, abrangendo cerca de 20.600 ha. Situa-se no extremo sul do Estado do Espírito Santo, no município de Alegre e pertence à bacia do rio Itapemirim. Com um relevo bastante movimentado, a região é marcada por uma paisagem fortemente ondulada e montanhosa, com pequenas extensões de afloramentos rochosos e vales em "V". Os seus fundos, na maioria das vezes, são colmatados pelo material proveniente das encostas. A hidrografia é composta por uma rede de drenagem densa, diversificada e altamente influenciada pela natureza geológica e topográfica do terreno, formando rios encaixados e algumas cachoeiras (Radambrasil, 1983).

$\mathrm{O}$ rio Alegre, curso d'água principal da bacia, deságua no rio Itapemirim (Instituto..., 2004). As altitudes máxima, média e mínima verificadas na área de estudo são, respectivamente, 1.245, 577 e $120 \mathrm{~m}$. As unidades de solo presentes na maior parte da bacia do rio Alegre são o Latossolo VermelhoAmarelo Distrófico (LVd3), os Cambissolos (LVd4), o Latossolo Vermelho-Amarelo Húmico (Lvd10), o Nitossolo (Trpe2) e o Argissolo (Pv3) (Brasil \& Espírito Santo, 1971; Embrapa, 1999). As terras no vale do ribeirão Arraial do Café e do rio Alegre apresentam aptidão agrícola regular para lavouras nos níveis de manejo $\mathrm{A}$ (práticas agrícolas que refletem baixo nível tecnológico) e $\mathrm{B}$ (práticas agrícolas que refletem nível tecnológico médio ). O restante da bacia apresenta terras com aptidão regular para pastagem plantada, considerando a utilização para o nível de manejo B. Estas terras também são aptas para culturas de ciclo longo e inaptas para culturas de ciclo curto (Brasil, 1979).

Pelas suas características naturais, a bacia do rio Alegre é apta para a silvicultura. $\mathrm{O}$ vale do ribeirão Arraial do Café e do rio Alegre é mais indicado para 
o uso agropecuário, embora comporte também a silvicultura. Isso se deve, principalmente, ao baixo risco à erosão de suas terras. Já o restante da bacia, embora admita o uso agropecuário com culturas de ciclo longo e pastagem, apresenta aptidão preferencial para a silvicultura, pois apresenta solos com baixa fertilidade e reserva de nutrientes e baixa capacidade de retenção de água (Dadalto et al., 1992; Espírito Santo, 1992). A ausência da cobertura florestal natural revela a intensa pressão de uso da terra nesta região. As matas foram devastadas e substituídas por culturas de subsistência e pela cafeicultura intensiva, principal atividade agrícola da bacia do rio Alegre. Ela é responsável pela geração da maior parte da renda e dos empregos (Instituto Brasileiro de Desenvolvimento Florestal, 1974, 1984; Lani, 1987; Resende et al., 1993).

Nas terras situadas acima de $600 \mathrm{~m}$ de altitude, o clima mais ameno, combinado com a presença de solos profundos corrigidos em sua acidez e fertilidade, torna o ambiente favorável ao cultivo do café arábica (Coffea arabica L.). O capim que melhor se adapta é o gordura ou meloso (Mellinis minutiflora) (Lani, 1987; Resende et al., 1993). As moradias são construídas geralmente nos terraços e mais próximas dos córregos, onde também são cultivadas as lavouras de subsistência de milho e feijão. $\mathrm{O}$ capim gordura não suporta um grande número de reses por hectare e não pode ser manejado com o uso de queimadas. Por isso, a pecuária visa principalmente à criação de gado leiteiro. A presença de água em abundância, o café e o gado leiteiro, que exigem numerosa mão de obra, o relevo acidentado que dificulta a mecanização e afasta o grande produtor rural, explicam a estrutura fundiária caracterizada por um grande número de pequenas propriedades na bacia do rio Alegre (Lani, 1987; Resende et al., 1993).

\subsection{Delimitação e quantificação das áreas de preservação permanente}

Para delimitar e quantificar a superfície das APPs, foram utilizadas as bases de dados digitais de altimetria e hidrografia. As suas tabelas de atributos são disponibilizadas por Nascimento (2004), no formato vetorial shapefile, estrutura de dados original do software ArcView ${ }^{\circ}$. Estas bases foram produzidas a partir das folhas topográficas digitais Divino de
São Lourenço (SF-24-V-A-IV-2), Guaçuí (SF-24V-A-IV-4), Anutiba (SF-24-V-A-V-1) e Muqui (SF24-V-A-V-3) (Instituto..., 2004). Realizou-se uma minuciosa verificação da consistência dos dados de altimetria e hidrografia. Em consulta ao CD Mapa Índice do Brasil - Mapeamento Geral do Brasil (Instituto..., 2003), verificou-se que o sistema de projeção cartográfica adotado pelo IBGE para as folhas Divino de São Lourenço, Guaçuí, Anutiba e Muqui, que contêm a bacia do rio Alegre, foi a Projeção Universal Transversa de Mercator (UTM), Datum horizontal Córrego Alegre (COA). A escala original destas folhas topográficas é de 1:50.000. Este sistema de projeção cartográfica e o respectivo referencial geodésico foram adotados no presente trabalho.

Utilizando-se a metodologia para delimitação automática desenvolvida por Ribeiro et al. (2002, 2006), foram delimitadas as seguintes categorias de APPs, em consonância com o disposto nos artigos $2^{\circ}$ e $3^{\circ}$ da Resolução $n^{\circ} 303$ do CONAMA: terço superior dos morros (APP-1), encostas com declividades superiores a $45^{\circ}$ (APP-2), entorno das nascentes e as suas áreas de contribuição (APP-3), margens dos cursos d'água (APP-4) e ao longo das linhas de cumeada, no terço superior das sub-bacias (APP-5).

Produziu-se uma base de dados digital no formato matricial (grade) para cada uma dessas cinco categorias de APP. As grades foram geradas com a resolução espacial de $10 \mathrm{~m}$, compatível com a exatidão cartográfica para a escala de 1:50.000 da base de dados de altimetria e hidrografia utilizada.

\subsection{Delimitação e quantificação das áreas de conflito de uso e ocupação da terra}

As classes de uso e ocupação da terra resultantes da intervenção humana nas áreas legalmente protegidas caracterizam as áreas de uso indevido. Logo, as análises desse estudo restringiram-se às seguintes classes: área agrícola, área edificada, cafezal, pastagem, reflorestamento, solo exposto e outros. A identificação e quantificação das eventuais áreas de conflito de uso e ocupação da terra foram obtidas pelo cruzamento das informações da base de dados digitais "Categorias de APPs" com as da base "Uso e Ocupação da Terra", disponibilizada por 
Nascimento (2004). Cada uma das grades relativas ao uso e ocupação da terra resultantes da intervenção humana foi multiplicada pela grade "Categorias de APPs", gerando-se assim a grade CF, que representa o mapa temático do Conflito de Uso e Ocupação da Terra.

O mapa temático dos distritos da bacia do rio Alegre foi produzido a partir da composição do limite da bacia, gerado automaticamente, com o limite distrital da Malha de Setor Censitário Rural Digital do Brasil - 2000. É um produto cartográfico do IBGE, compatível com a escala de 1:2.500.000, gerado a partir do Arquivo Gráfico Municipal AGM - composto pelas folhas topográficas na melhor escala disponível para as diversas regiões do País. Analisando-se a Malha de Setor Censitário Rural Digital do Brasil, verificou-se que as linhas definidoras dos limites distritais, para a região da bacia do rio Alegre, são formadas pelos cursos d'água e pelos divisores topográficos. Então, no ambiente de edição do Arc/INFO', os limites dos distritos foram ajustados em função da hidrografia e da altimetria das folhas topográficas disponibilizadas pelo IBGE na escala de 1:50.000, para torná-los compatíveis com essa escala, adotada para todas as etapas desse trabalho.

\subsection{Valoração econômica das APPs}

A bacia do rio Alegre é formada pelos distritos Café, Celina, Alegre (sede) e Rive. Para cada um destes distritos, foi determinado o preço médio de mercado das suas terras, tomando-se por base o "Quadro de Preços" da Prefeitura Municipal de Alegre-ES. Para se estimar o impacto financeiro na economia regional, i. e., a remuneração auferida pelos produtores rurais nas áreas protegidas, utilizou-se a fórmula de Faustmann (1849) (Equação 1):

$$
\mathrm{VET}=\mathrm{a}_{\mathrm{w}} \frac{1}{(1+\mathrm{i})^{\mathrm{w}}-1}
$$

em que: $V E T=$ valor esperado da terra $[\mathrm{R} \$], a_{\mathrm{w}}=$ remuneração líquida auferida a cada período $w$ [R $\$$, $i=$ taxa anual de juros, e $w=$ período de ocorrência das parcelas.

\section{RESULTADOS E DISCUSSÕES}

\section{1. Áreas de preservação permanente}

A Figura 1 apresenta o resultado do mapeamento automático das APPs identificadas na área de estudo.

As APPs ocupam uma área de 9.428 ha (46\%) de um total de 20.566 ha da área da bacia. A categoria de APPs que ocupa a maior área é dos divisores d'água (APP-5, 55\%), seguida pelas zonas ripárias (APP-4, 29\%), proteção de nascentes (APP-3, 15\%), topos de morros (APP-1, 0,5\%) e encostas íngremes (APP-2, $0,1 \%)$.

Dentro dos limites da bacia do rio Alegre foi mapeada uma área de 2.880 ha de fragmentos florestais e, deste total, 1.694 ha estavam dentro das áreas legalmente protegidas.

\subsection{Delimitação e quantificação das áreas de uso indevido}

A Figura 2 apresenta, além das APPs preservadas, o mapa de Conflito do Uso e Ocupação da Terra em relação às categorias de APPs.

Atualmente, 7.290 ha, correspondendo a 77\% do total das APPs, estão sob conflito de uso e ocupação na bacia do rio Alegre. Consequentemente, apenas 23\% do total de APPs, i.e., 2.140 ha, estão efetivamente preservados. Analisando-se os dados da Tabela 1, verifica-se que as classes Pastagem e Cafezal ocupam a maior parte das áreas de conflito de uso, com 5.966 ha (82\%) e 980 ha (13\%), respectivamente. Já as classes identificadas como Outros e Reflorestamento, contribuem com apenas 3,3 ha $(0,05 \%)$ e 6,5 ha $(0,1 \%)$, respectivamente. Além disso, observa-se que as APPs mais afetadas pela intervenção humana ocorrem ao longo das linhas de cumeada, no terço superior das sub-bacias (APP-5), com 3.786 ha (52\%) e nas margens dos cursos d'água (APP-4) com 2.402 ha (33\%).

\subsection{Preço médio das terras por distrito da bacia do rio Alegre}

Com relação ao preço médio das terras por distrito da bacia do rio Alegre, observou-se que os valores mais altos encontram-se no distrito Alegre, sede do município, onde o preço médio das terras é de 


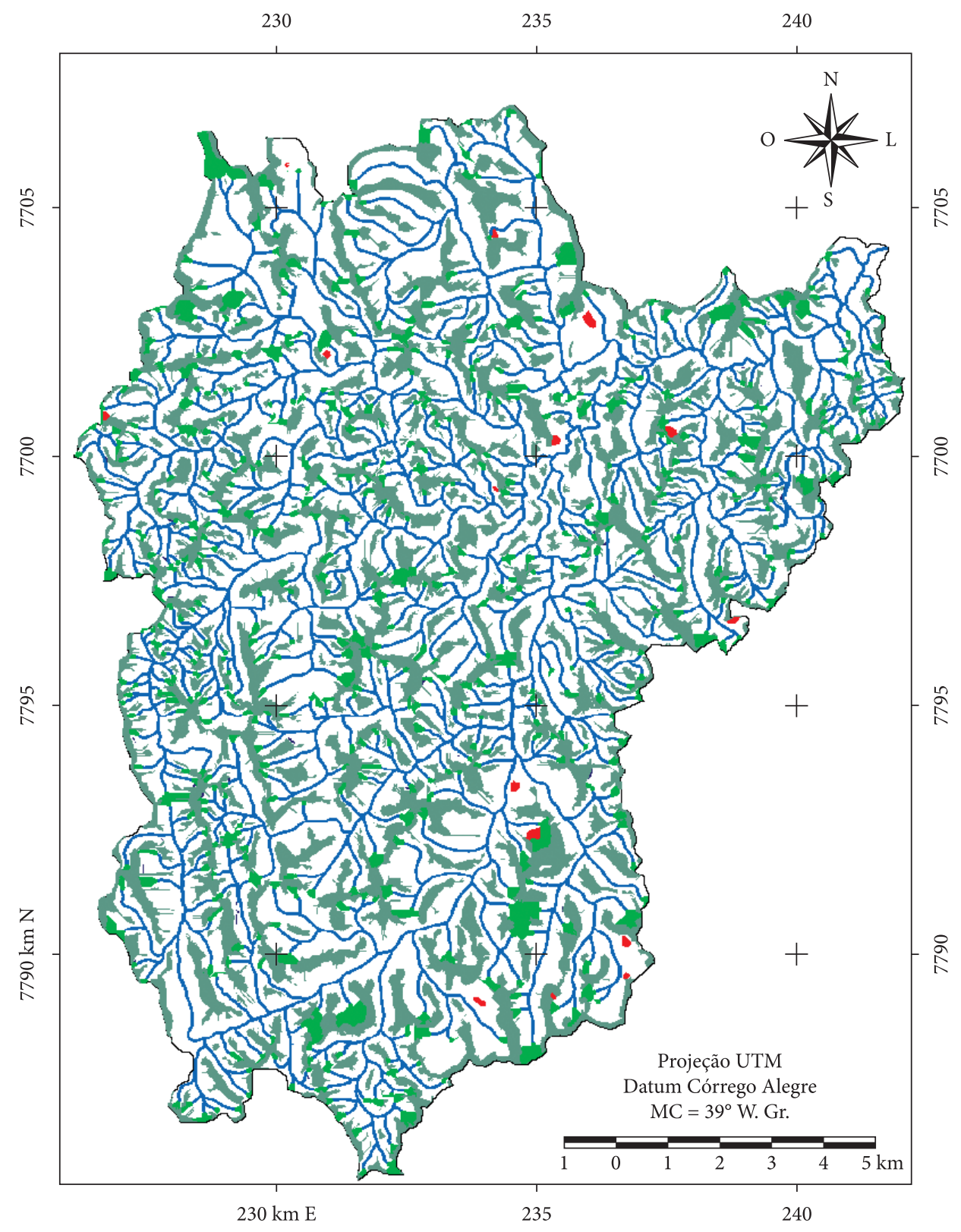

$\square$ APP - 1 - APPs situadas no terço superior dos morros
APP - 2 - APPs situadas nas encostas com declividade superior a $45^{\circ}$
$\square$ APP - 3 - APPs situadas no entorno das nascentes e suas áreas de contribuição
$\square$ APP - 4 - APPs situadas nas margens dos cursos d'água
$\square$ APP - 5 - APPs situadas ao longo das linhas de cumeada, no terço superior das sub-bacias
$\square$ Áreas de reserva legal e uso permitido

Figura 1. Localização das APPs na bacia do Rio Alegre, Alegre-ES.

Figure 1. Location of PPA's in the basin of the Alegre River, Alegre-ES. 


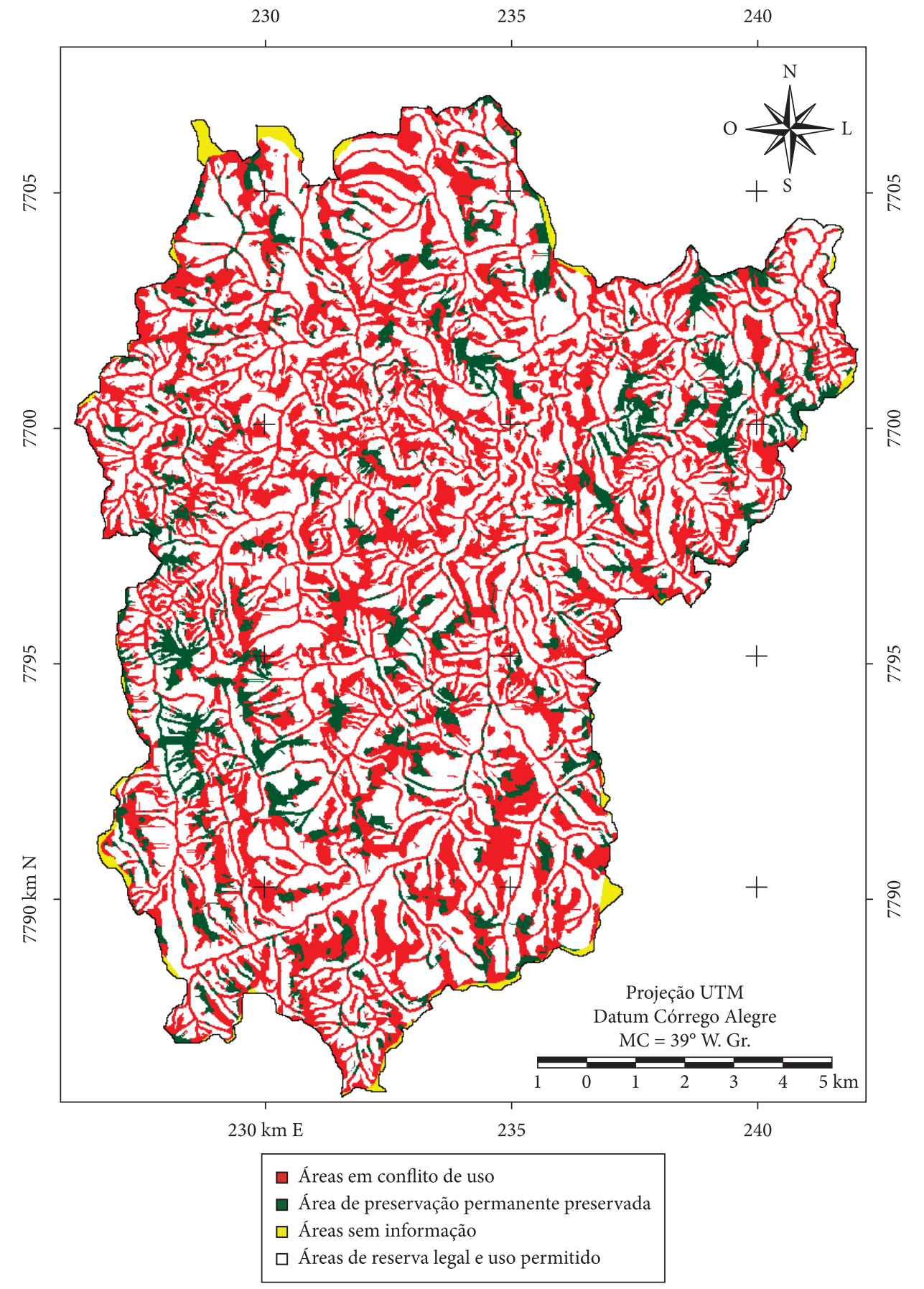

Figura 2. Conflito de uso e ocupação da terra na bacia do rio Alegre, Alegre-ES. Figure 2. Conflict of legal use of land within the Alegre River basin, Alegre-ES. 
Tabela 1. Quantificação da ocorrência de conflito de uso da terra nas categorias de APPs delimitadas na bacia do rio Alegre, município de Alegre-ES.

Table 1. Quantification of the occurrence of a legal conflict of land use, defined per categories of PPA, in the Alegre River basin, Alegre-ES.

\begin{tabular}{|c|c|c|c|c|c|c|c|c|}
\hline \multirow{3}{*}{\multicolumn{2}{|c|}{$\begin{array}{l}\text { Classes de uso } \\
\text { e ocupação da terra }\end{array}$}} & \multicolumn{5}{|c|}{ Categorias de APPs } & \multirow{2}{*}{\multicolumn{2}{|c|}{$\begin{array}{l}\text { Total } \\
\text { Área }\end{array}$}} \\
\hline & & \multicolumn{5}{|c|}{ Área (ha) } & & \\
\hline & & APP-1 & APP-2 & APP-3 & APP-4 & APP-5 & ha & $\%$ \\
\hline \multirow{7}{*}{$\begin{array}{l}\text { Sistema } \\
\text { antrópico }\end{array}$} & Área agrícola & & 0,14 & 32,83 & 37,99 & 61,39 & 132,35 & 1,82 \\
\hline & Área edificada & 0,17 & & 6,98 & 47,29 & 18,47 & 72,91 & 1,00 \\
\hline & Cafezal & & 1,37 & 155,72 & 214,97 & 607,03 & 979,09 & 13,43 \\
\hline & Outros & & & 0,55 & 2,74 & 0,04 & 3,33 & 0,05 \\
\hline & Pastagem & 25,50 & 4,81 & 854,86 & $2.043,31$ & $3.037,10$ & $5.965,58$ & 81,85 \\
\hline & Reflorestamento & & & 0,16 & 1,78 & 4,57 & 6,51 & 0,09 \\
\hline & Solo exposto & & & 17,03 & 54,39 & 57,5 & 128,92 & 1,77 \\
\hline \multicolumn{2}{|l|}{ Total } & 25,67 & 6,32 & $1.068,13$ & $2.402,47$ & $3.786,10$ & $7.288,69$ & \\
\hline \multicolumn{2}{|l|}{$\%$} & 0,35 & 0,09 & 14,65 & 32,96 & 51,94 & & 100,00 \\
\hline
\end{tabular}

$\mathrm{R} \$ 1.267 \cdot \mathrm{ha}^{-1}$. Os distritos Celina, com R\$ 1.100.ha $\mathrm{h}^{-1}$, e Café, com R\$1.074.ha ${ }^{-1}$, os situados no limite do município, mais afastados da sede e com relevo mais ondulado, apresentam os valores mais baixos. Os preços médios das terras nos distritos Rive, Celina e Café correspondem, respectivamente, a 91, 87 e 85\% do valor médio das terras da sede do município de Alegre, de acordo com o "Quadro de Preços" dos imóveis.

\subsection{Valoração econômica total das áreas de conflito de uso e ocupação da terra}

Como pode ser observado a partir dos dados da Tabela 2, o distrito Alegre tem 2.180 ha de áreas de conflito em APPs. Combinado com o maior valor de mercado de suas terras, isso fez com que este distrito apresentasse o maior valor total ( $\mathrm{R} \$ 2.760 .540)$ para as áreas com conflito de uso e ocupação na bacia do rio Alegre. O distrito Café, com $18 \%$ a mais de área de conflito em relação à da sede do município, apresentou um valor total de $\mathrm{R} \$ 2.757 .285$, inferior em $0,12 \%$ ao da sede. Isso é explicado pelo fato de as terras de Café terem o menor valor de mercado entre os preços médios dos distritos estudados. A categoria de APP que causa o maior impacto na economia local da bacia do rio Alegre é a proteção do terço superior das encostas (APP-5), com um valor total de $\mathrm{R} \$ 4.322 .140$. Já a categoria de APP de menor impacto econômico é aquela associada à proteção das encostas íngremes (APP-2), com um valor total de $\mathrm{R} \$ 7.058$. O valor total das áreas com conflito de uso e ocupação das terras na bacia do rio
Alegre ( $\mathrm{R} \$$ 8.322.066), dividido pela soma dessas áreas, representou um valor médio de $\mathrm{R} \$ 1.142 . \mathrm{ha}^{-1}$, valor este bem próximo do preço médio das terras da bacia do rio Alegre ( $\left.\mathrm{R} \$ 1.148 \cdot \mathrm{ha}^{-1}\right)$.

Na Tabela 3, os dados indicam que Café, distrito com a maior área territorial (7.300 ha), apresentou a maior área de conflito de uso e ocupação da terra, totalizando 2.570 ha, o que equivale a $76 \%$ da área de preservação permanente desse distrito (3.400 ha). Essa tendência mantém-se para os distritos Celina, Alegre e Rive. Este último, com a menor área territorial (520 ha), apresentou a menor área de conflito de uso e ocupação da terra, totalizando 170 ha, o que equivale a $78 \%$ da área de preservação permanente deste distrito (220 ha). Isso atesta a violação generalizada do Código Florestal em toda a bacia do rio Alegre, não se observando tendências de concentração da violação.

\subsection{Impacto econômico total anual da implantação das APPs na economia regional}

O valor das APPs usadas para atividades produtivas totaliza $\mathrm{R} \$ 8.322 .066,01$. Para uma economia de base anual, esse montante pode ser transformado em anuidade equivalente. A Tabela 4 apresenta os valores dessas anuidades, calculados para diferentes taxas de juros de mercado.

A análise dos dados da Tabela 4 mostra que, para uma taxa de juros de mercado de $12 \%$ a.a., a remuneração anual das áreas usadas na produção 
Tabela 2. Valoração econômica das áreas com uso indevido, tendo por base o preço médio de mercado das terras, na bacia do rio Alegre, município de Alegre - ES.

Table 2. Valuation of areas facing legal land use conflict, based on the average market price of land.

\begin{tabular}{|c|c|c|c|c|}
\hline APPs & Distrito & Área (ha) & Preço $\left(\mathbf{R} \$ . h \mathbf{a}^{-1}\right)$ & Total (R\$) \\
\hline \multirow{5}{*}{ APP1 } & Alegre (sede) & 7,58 & $1.266,64$ & $9.601,13$ \\
\hline & Café & 12,54 & $1.073,68$ & $13.463,95$ \\
\hline & Celina & 5,55 & $1.100,04$ & $6.105,22$ \\
\hline & Rive & & $1.151,67$ & \\
\hline & Subtotal & 25,67 & & $29.170,30$ \\
\hline \multirow{5}{*}{ APP2 } & Alegre (sede) & 1,16 & $1.266,64$ & $1.469,30$ \\
\hline & Café & 3,74 & $1.073,68$ & $4.015,56$ \\
\hline & Celina & 1,20 & $1.100,04$ & $1.320,05$ \\
\hline & Rive & 0,22 & $1.151,67$ & 253,37 \\
\hline & Subtotal & 6,32 & & $7.058,28$ \\
\hline \multirow{5}{*}{ APP3 } & Alegre (sede) & 283,31 & $1.266,64$ & $358.851,78$ \\
\hline & Café & 372,06 & $1.073,68$ & $399.473,38$ \\
\hline & Celina & 377,73 & $1.100,04$ & $415.518,11$ \\
\hline & Rive & 35,03 & $1.151,67$ & $40.343,00$ \\
\hline & Subtotal & $1.068,13$ & & $1.214 .186,27$ \\
\hline \multirow{5}{*}{ APP4 } & Alegre (sede) & 734,97 & $1.266,64$ & $930.942,40$ \\
\hline & Café & 761,64 & $1.073,68$ & $817.757,64$ \\
\hline & Celina & 822,01 & $1.100,04$ & $904.243,88$ \\
\hline & Rive & 83,85 & $1.151,67$ & $96.567,53$ \\
\hline & Subtotal & $2.402,47$ & & $2.749 .511,45$ \\
\hline \multirow{5}{*}{ APP5 } & Alegre (sede) & $1.152,40$ & $1.266,64$ & $1.459 .675,94$ \\
\hline & Café & $1.418,09$ & $1.073,68$ & $1.522 .574,87$ \\
\hline & Celina & $1.163,91$ & $1.100,04$ & $1.280 .347,56$ \\
\hline & Rive & 51,70 & $1.151,67$ & $59.541,34$ \\
\hline & Subtotal & $3.786,10$ & & $4.322 .139,71$ \\
\hline \multirow{5}{*}{$\begin{array}{l}\text { APP total com } \\
\text { uso indevido }\end{array}$} & Alegre (sede) & $2.179,42$ & $1.266,64$ & $2.760 .540,55$ \\
\hline & Café & $2.568,07$ & $1.073,68$ & $2.757 .285,40$ \\
\hline & Celina & $2.370,40$ & $1.100,04$ & $2.607 .534,82$ \\
\hline & Rive & 170,80 & $1.151,67$ & $196.705,24$ \\
\hline & Total & $7.288,69$ & & $8.322 .066,01$ \\
\hline
\end{tabular}

Tabela 3. APPs e áreas de conflito de uso em relação às áreas dos distritos do município de Alegre - ES.

Table 3. PPAs and areas with a legally conflicting use in each of the districts.

\begin{tabular}{|c|c|c|c|c|c|}
\hline \multirow{2}{*}{ Distrito } & \multirow{2}{*}{ Área (ha) } & \multirow{2}{*}{ APP (ha) } & \multirow{2}{*}{$\%$} & \multicolumn{2}{|c|}{ Área de conflito } \\
\hline & & & & Área (ha) & $\%$ em APP \\
\hline Alegre (sede) & $6.298,23$ & $2.858,88$ & 45,4 & $2.179,42$ & 76,2 \\
\hline Café & $7.298,50$ & $3.394,69$ & 46,5 & $2.568,07$ & 75,6 \\
\hline Celina & $6.451,88$ & $2.954,35$ & 45,8 & $2.370,40$ & 80,2 \\
\hline Rive & 517,68 & 220,50 & 42,6 & 170,80 & 77,5 \\
\hline Total & $20.566,29$ & $9.428,42$ & 45,8 & $7.288,69$ & 77,3 \\
\hline
\end{tabular}

Tabela 4. Anuidade equivalente para a região da bacia do Rio Alegre, Alegre - ES.

Table 4. Equivalent annuity for land use in the Alegre River basin, Alegre-ES.

\begin{tabular}{cccc} 
Taxa de juros (a.a.) & $\mathbf{6 \%}$ & $\mathbf{9 \%}$ & $\mathbf{1 2 \%}$ \\
\hline Valor & $\mathrm{R} \$ 500.000$ & $\mathrm{R} \$ 750.000$ & $\mathrm{R} \$ 1.000 .000$ \\
\hline
\end{tabular}


agropecuária deve ser de R 1 milhão. Em outras palavras, a fiel observância do Código Florestal, com proteção de fato das APPs da bacia do rio Alegre, retiraria da economia local um montante equivalente a $\mathrm{R} \$ 137,01 \cdot \mathrm{ha}^{-1} \cdot \mathrm{ano}^{-1}$ ou seja, exatos $\mathrm{R} \$ 10,83 \cdot \mathrm{ha}^{-1} \cdot \mathrm{mê}^{-1}$. Esse valor representa o aluguel mensal de cada hectare das áreas de proteção ambiental utilizadas para a produção agropecuária.

Corrêa (2006), analisando o impacto econômico do cumprimento efetivo da legislação ambiental e florestal quanto às APPs e à reserva legal na sub-bacia do rio Pomba, no município de Rio Pomba, verificou que o produtor deixaria de auferir $\mathrm{R} \$ 341,83 \cdot \mathrm{ha}^{-1} \cdot \mathrm{ano}^{-1}$ para cada hectare em que forem efetivadas a APP e a reserva legal. Entretanto, a sociedade organizada, quando opta por preservar permanentemente as áreas assim caracterizadas na legislação ambiental, reconhece nelas um valor intrínseco no mínimo superior à melhor das alternativas de exploração econômica.

Mattos et al. (2007), por exemplo, verificaram que cada domicílio do município de Viçosa -MG está disposto a pagar $\mathrm{R} \$ 27,98$ pela preservação ou recuperação das áreas de preservação permanente da microbacia do ribeirão São Bartolomeu, o que resulta em um montante anual de $\mathrm{R} \$ 3.863 .926,08$, que representam $\mathrm{R} \$ 3.616,52 \cdot \mathrm{ha}^{-1} \cdot$ ano $^{-1}$ para a recuperação e/ou preservação dessas áreas.

\section{CONCLUSÕES}

Os resultados do presente trabalho permitem concluir que:

- da bacia de contribuição do rio Alegre, 77\% são APPs e, desses, apenas $23 \%$ encontramse atualmente preservados. Isso demonstra o alto nível de omissão sistemática do Estado no cumprimento da lei;

- o valor total das APPs usadas para atividades produtivas totaliza $\mathrm{R} \$ 8,3$ milhões;

- a categoria de APP cuja imposição legal causará maior impacto na economia local da bacia do rio Alegre é a situada ao longo das linhas de cumeada. Por outro lado, a APP cuja imposição legal trará o menor impacto econômico está associada às encostas com declividades superiores a $45^{\circ}$;

- para uma taxa de juros de $12 \%$ a.a., a anuidade equivalente dasáreas com uso indevido, em relaçãoàs APPs, é de R \$ 1 milhão. Esse valor equivale a cerca de
$\mathrm{R} \$ 140 . \mathrm{ha}^{-1} \cdot$ ano $^{-1}$, ou seja, a contribuição mensal líquida de cada hectare de APP desmatado à economia da região da bacia do Rio Alegre é de apenas $\mathrm{R} \$ 11$

Assim, considerando-se a estrutura fundiária da bacia do rio Alegre, composta por um grande número de pequenas propriedades rurais, e a contribuição líquida mensal de R\$ 11 por hectare de APP desmatado, cai por terra o mito de que a imposição do Código Florestal Brasileiro inviabilizará economicamente o pequeno produtor agrícola. Esse valor exigiria cerca de 38 ha para se conseguir uma renda equivalente a um salário mínimo ( $\mathrm{R} \$ 415,00)$. Tais cifras denotam que a implementação de políticas efetivas de estímulo à preservação ambiental da bacia do rio Alegre é perfeitamente viável, mesmo na esfera do poder municipal.

Ressalta-se ainda que o que inviabiliza a agropecuária é a forma de exploração das propriedades, e não a aplicação da legislação relativa às APPs eà reserva legal. A renda gerada pela incorreta exploração das áreas ambientalmente protegidas não eleva o nível de vida dos produtores rurais, ao contrário, escraviza-os ao exaurir os recursos dos quais dependem de forma cruel. O estímulo à preservação dessas áreas acarretaria uma valorização da figura do pequeno produtor, o desenvolvimento de novas atividades econômicas, como o turismo e o artesanato, que têm impacto ambiental reduzido em relação à agricultura, trazendo novos recursos para a zona rural, fixando o homem no campo, dando-lhe dignidade.

\section{AGRADECIMENTOS}

Ao Conselho Nacional de Desenvolvimento Científico e Tecnológico (CNPq) e à Coordenação de Aperfeiçoamento de Pessoal de Nível Superior (CAPES) pelo financiamento e à Universidade Federal de Viçosa pelo fornecimento da estrutura e pessoal.

\section{STATUS DA SUBMISSÃO}

Recebido: 05/08/2008 


\section{AUTOR(ES) PARA CORRESPONDÊNCIA}

\section{Carlos Antonio Alvares Soares Ribeiro}

Departamento de Engenharia Florestal - DEF, Universidade Federal de Viçosa - UFV,

Av. Peter Henry Rolfs, s/n,

Campus Universitário, CEP 36570-000,

Viçosa, MG, Brasil

e-mail: cribeiro@ufv.br

\section{REFERÊNCIAS}

Benjamin AHV. Desapropriação, reserva legal e áreas de preservação permanente. [online]. Rev CEJ 2000; 3 [cited 2004 jun. 30]. Available from: http://www.cjf.gov. br/revista/numero3/artigo04.htm.

Brasil. Lei Federal no 4.771, de 15 de setembro de 1965. Institui o Novo Código Florestal Brasileiro. Diário Oficial da República Federativa do Brasil, Brasília, DF (1965 set. 16).

Brasil. Ministério da Agricultura. Departamento Nacional de Pesquisa Agropecuária. Divisão de Pesquisa Pedológica, Espírito Santo. Secretaria da Agricultura do Estado do Espírito Santo. Divisão de Experimentação e Pesquisa em convênio com o IBC/GERCA. Carta de levantamento de reconhecimento dos solos do Estado do Espírito Santo, escala 1:400.000, Projeção Policônica; 1971.

Brasil. Ministério da Agricultura. Secretaria Geral. Secretaria Nacional de Planejamento Agrícola SUPLAN. Carta de Aptidão Agrícola das terras do Estado do Espírito Santo, escala 1:400.000, Projeção Policônica. Brasília, DF: SUPLAN; 1979.

Corrêa JBL. Quantificação das áreas de preservação permanente e reserva legal e de seus impactos econômicos na Bacia do Rio Pomba em Minas Gerais [dissertação]. Universidade Federal de Viçosa; 2006.

Dadalto GG, Barbosa CA, Sartori M. Aptidão florestal das terras do Estado do Espírito Santo. Vitória, ES; 1992.

Empresa Brasileira de Pesquisa Agropecuária EMBRAPA. Centro Nacional de Pesquisa de Solos. Sistema Brasileiro de Classificação de Solos. Brasília, DF: EMBRAPA; 1999.

Espírito Santo. Secretaria de Estado do Desenvolvimento Econômico. Fórum Sócio-Econômico do Espírito Santo. Carta de aptidão florestal das terras do Estado do Espírito Santo, escala 1:400.000, projeção universal transversa de mercator, M.C. $=39^{\circ} W$. Gr. Vitória, ES; 1992.
Instituto Brasileiro de Desenvolvimento Florestal IBDF. Inventário florestal nacional: florestas nativas. Rio de Janeiro - Espírito Santo. Brasília, DF: IBDF; 1984.

Instituto Brasileiro de Desenvolvimento Florestal IBDF. Zoneamento Econômico Florestal do Estado do Espírito Santo. Belo Horizonte, MG: IBDF; 1974.

Instituto Brasileiro de Geografia e Estatística - IBGE. Cartas topográficas do mapeamento sistemático: Anutiba, Divino de São Lourenço, Guaçuí e Muqui, escala varia, projeção universal transversa de mercator, M.C. $=39^{\circ}$ W. Gr. [online] [cited 2004 nov. 10] Available from: http://www.ibge.gov.br.

Instituto Brasileiro de Geografia e Estatística - IBGE. Mapa de vegetação do Brasil, escala 1:5.000.000, Projeção Policônica, M.C. = 54º W. Gr. Brasília, DF: IBGE; 1993.

Instituto Brasileiro de Geografia e Estatística - IBGE. Mapa índice do Brasil: mapeamento geral do Brasil, escala varia, Projeção Policônica. [CD-ROM]. 2. ed. Rio de Janeiro, RJ: IBGE; Brasília, DF: Diretoria de Serviço Geográfico; 2003.

Lani JL. Estratificação de ambientes na bacia do Rio Itapemirim, no sul do Estado do Espírito Santo [dissertação]. Viçosa, MG: Universidade Federal de Viçosa - UFV; 1987.

Mattos AD, Jacovine LAG, Valverde SR, Souza AL, Silva ML, Lima JE. Valoração ambiental de áreas de preservação permanente da Microbacia do ribeirão São Bartolomeu no município de Viçosa, MG. Revista Árvore 2007; 31(2): 347-353.

Nascimento MC. Mapeamento das áreas de preservação permanente e dos conflitos de uso da terra na bacia hidrográfica do Rio Alegre, ES [dissertação]. Viçosa: Universidade Federal de Viçosa - UFV; 2004.

Radambrasil. Ministério das Minas e Energia. Levantamento de recursos naturais. Rio de Janeiro; 1983. Folha SF. 23/24, v. 32.

Resende M, Lani JL, Cerqueira AF. Bacia do Rio Itapemirim: aspectos ecológicos. Brasília, DF: Secretaria de Assuntos Estratégios; Viçosa, MG: Universidade Federal de Viçosa; Vitória, ES: EMCAPA; 1993.

Ribeiro CAAS, Oliveira MJ, Soares VP, Pinto FAC. Delimitação automática de áreas de preservação permanente em topos de morros e em linhas de cumeada: metodologia e estudo de caso. In Anais do $V$ Seminário de Atualização em Sensoriamento Remoto e Sistemas de Informações Geográficas Aplicadas à Engenharia Florestal; 2002; Curitiba, PR. Curitiba, PR; 2002. p. 7-18.

Ribeiro CAAS, Soares VP, Oliveira AMS, Gleriani JM. O desafio da delimitação de áreas de preservação permanente. Revista Árvore 2006; 29(2): 203-212. 